\title{
An Alternative Technique to Determine Vertical Dimension of Occlusion From Anthropometric Study Done in Gujarati Population
}

\author{
Dr.Rupal Shah ${ }^{1}$,Dr Sanjay Lagdive ${ }^{2}$,Dr. Pratik Acharya ${ }^{3}$, Dr. Dipak Solanki ${ }^{4}$, \\ Dr. Sunil Shrof ${ }^{5}$, Dr. Sejal Mehta ${ }^{6}$, Dr Ekta Khirsariya ${ }^{7}$, Mr. Ghanshyam Patel ${ }^{8}$ \\ ${ }^{I}$ (Professor \& Head of Department,Department of Prosthodontics \& Crown \& Bridge, Govt. Dental College \\ \&Hospital, Ahmedabad/ Gujarat University, India) \\ 2(Professor, Department of Prosthodontics \& Crown \& Bridge, Govt. Dental College \& Hospital, Ahmedabad/ Gujarat \\ University, India) \\ 3,4,5,6(Post Graduate Student, Department of Prosthodontics \& Crown \& Bridge, Govt. Dental College \& Hospital, \\ Ahmedabad/ Gujarat University, India) \\ ${ }^{7}$ (under graduate student, Govt. Dental College \& Hospital, Ahmedabad/ Gujarat University, India) \\ ${ }^{8}$ (biostatistian, gujarat university)
}

\begin{abstract}
:
Purpose: The aim of this study was to find the correlation between vertical dimension of occlusion (VDO) with length of fingers and distance from hair line to nasion.

Materials and Methods: A cross- ${ }^{-}$sectional study was conducted on 400 dentate subjects comprising of 200 males and 200 females. Anthropometric measurements of VDO, length of index finger, length of little finger and distance from hair line to nasion were recorded clinically using digital vernier caliper. Correlation between VDO and length of fingers and distance from hair line to nasion was studied using Pearson's correlation method.

Results: VDO was significantly and positively correlated with all the parameters studied in females but not in males. In females, VDO had strongest correlation for length of little finger $\left(\mathrm{r}^{-} 0.550, \mathrm{p}\right.$ value $\left.<0.001\right)$ followed by length of index finger(r-0.413, $\mathrm{p}$ value<0.001), measured distance from hairline to nasion $(\mathrm{r}-0.294, \mathrm{p}$ value<0.001) in the Gujarati populations. In males VDO was correlated with length of little finger $(\mathrm{r}-0.375, \mathrm{p}$ value $<0.001)$ but not with other 2 parameters studied.

Conclusion: In females, pearson's correlation for little finger is 0.550 and $p$ value is less than 0.001 , so length of liitle finger is the best parameter to predict VDO in females. Prediction of VDO through this method is reliable, and reproducible, this method is also simple, economic, and non-invasive; hence, it could be recommended for everyday practice.
\end{abstract}

Abbreviations

$\mathrm{VDO}=$ vertical dimension at occlusion

\section{Introduction}

In the $21^{\text {st }}$ century, oral rehabilitation of edentulous patients either by complete dentures or by implants prosthesis has made prosthodontists to find the accurate, simple and less time consuming procedure to determine vertical dimension of occlusion (VDO).Recording the correct vertical jaw relation is a crucial step in constructing complete denture.

Improper estimation of vertical dimensions of occlusion (VDO) can lead to rapid resorption of the residual alveolar ridges. This critical step in complete denture fabrication, has encouraged many prosthodontists to find a plausible anthropometric measurement within the face. Vertical dimensions of the face show infinite variables in a dentulous patient and are dependent on multiple factors. The problem with edentulous state magnifies because the vertical dimension associated with 'sinking-in' of the lips is greater than the occlusal vertical dimension made before the teeth were extracted.

Glossary of Prosthodontic Terms defines vertical dimension, as the distance between the two selected anatomic landmarks or marked points (usually one on the tip of the nose and the other upon the chin), one on a fixed member and other one on a movable member ${ }^{1}$. Dentist must establish an appropriate lower facial height when lost, which should be within the range of patient's acceptability. If VDO is not measured properly and it is either high or too low, it will not let the patients to do all functions properly. Prosthodontics have been proposing and using several techniques to estimate VDO. However, none of them has proven more scientific accuracy than others. Each method advocated has its own limitations.

Anthropometric measurements ${ }^{16}$ were used to determine proportions of body parts since antiquity, when sculptors and mathematicians followed the golden proportion which later specified as a ratio of $1.618^{6}$. Leonardo Da Vinci and $\mathrm{McGee}^{5}$ correlated VDO with various anthropometric measurements. According to them, original VDO is most often similar to the distance from the outer canthus of one eye to the inner canthus of the other eye, vertical height of the ear, twice the length of one eye, horizontal distance between the pupils, and vertical length of nose at the midline and, distance from hairline to centre of eye-brow, and also have correlations with height of person ${ }^{18}$. In line with these observations, this study was designed to assess the possibility of any correlation between VDO and length of fingers ${ }^{17}$, distance from hairline to nasion in the Indian population so that it can be served as a simple and precise method for estimating VDO.

\section{Material and Method}

For this study, Clearance from the Institutional Ethical committee was obtained. Four hundred physically healthy dentate subjects composed of 200 males and 200 females with the age range of 20 to 30 years having no deformity of fingers or face were selected randomly from government dental college and hospital, Ahmedabad, Gujarat, India. These age parameters were decided because within these ages, growth of body has completed proportionally and all the teeth are 
erupted at level of occlusal plane. After these ages, there may be chance of attrition of teeth, which can cause alteration of vertical dimension

All the participants had class I jaw relationship and a definite centric stop with at least 28 teeth fully erupted, periodontally sound teeth in both jaws. Subjects with the following conditions were not included for the study: Open bite or deep bite cases, teeth anomalies, attrition, extensive prosthesis or restorations in the oral cavity, temporomandibular joint disorders, or any other pathology in the maxillofacial region, history of trauma, orthodontic treatment or orthognathic surgery.

All subjects provided written informed consent to participate in the study. Anthropometric measurements of vertical dimension of occlusion, length of index finger, little finger and distance from hair line to nasion were recorded clinically in millimeters using a digital Vernier Caliper with an accuracy of $0.01 \mathrm{~mm}$.

As seen in figure 1, Length of the index finger of right hand was measured on palmar aspect in supination from tip of finger to the near most point on palmar digital crease with digital caliper. In the same way, As seen in figure 2, length of little finger of right hand was measured from tip of finger to the farther most point on palmar digital crease. The measurements were taken with the hand straight and flat. While taking all these finger measurements it was made sure that nails of the subjects were trimmed. As seen in figure 3, distance from hairline to nasion was also recorded with Vernier Caliper. As seen in figure 4, to record VDO, the subjects were instructed to bite in occlusion. The lower tip of caliper was placed firmly below the chin so that the soft tissues were compressed by pressure exerted and thus caliper can come as close as possible to the lower border of mandible against the skin and upper tip is raised till it touches the base of nasal septum.

For all the parameters of the study, mean was calculated. Correlation was studied by Pearson Correlation method. For the execution of regression command and preparation of a prediction equation to estimate VDO Statistical Package for Social Sciences (SPSS) Software was used.

\section{Results}

Descriptive statistics of the parameters studied, is presented in Table 1. From Table 1, it was observed that, in males the mean value of VDO was $62.20 \mathrm{~mm}$, Where as in female, the mean value was $57.71 \mathrm{~mm}$. Thus, males have higher VDO compare to females.

In males, the mean value of length of index finger was $70.20 \mathrm{~mm}$ whereas in females, it was $66.99 \mathrm{~mm}$. Thus, males have longer index finger as compared to females. In males, the mean value of length of little finger was $59.99 \mathrm{~mm}$. Whereas in females; the mean value was $56.90 \mathrm{~mm}$.

The Coefficient of Correlation (r) by Pearson between the measured variables and VDO are presented in Table 2. From Table 2, it was observed that in males and females, VDO is significantly and more positively correlated with length of little finger studied. In males, correlation of VDO was stronger for the length of little finger $(r=0.375$, $p$ value $<0.000)$. In females, correlation of VDO was strongest for the length of little finger $(r=0.550, p$ value $<0.000)$. VDO is also partially positively correlated with distance from hair line to nasion both in male $(\mathrm{p}$ value $=0.004)$ and female $(\mathrm{p}$ value $=0.000)$. However, VDO is also positively correlated with length of index finger(p-value $=0.000)$ only in females not in males(pvalue $=0.105$ ).

Determination of VDO using regression equation from Table 3, for length of index finger had a standard error of \pm 7.80 and \pm 4.00 in males and females respectively. Determination of VDO using regression equation for length of little finger had a standard error of \pm 7.28 and \pm 3.67 in males and females respectively. Determination of VDO using regression equation dimension from hairline to nasion had a standard error of \pm 7.70 and \pm 4.20 in males and females respectively. So in females by these results standard error is less than 5 in all parameters studied as given in Table 3 , so we concluded that VDO in females strongly correlated with little fingers but partially correlated with the distance from hairline to nasion and length of index finger.

In males following regression equations were reliable to determine VDO:

$\mathrm{Y}=45.47+0.271 * \mathrm{~A}, \quad \mathrm{Y}=55.93+0.089 * \mathrm{~B}, \mathrm{Y}=22.59+0.660 * \mathrm{C}$

In females following regression equations were reliable to determine VDO:

$\mathrm{Y}=44.96+0.211^{*} \mathrm{~A}, \mathrm{Y}=30.61+0.404 * \mathrm{~B}, \mathrm{Y}=20.39+0.656 * \mathrm{C}$

\section{Discussion}

Unquestionably, establishing a correct vertical dimension of face is one of the important factors to be considered. Literature review depicted that many methods have been described and used by professionals over the years for the purpose of vertical dimension determination, but none of them is fully accepted or considered completely correct.

Physiological rest position of the mandible and the freeway space form the basis of vertical dimension estimation and has been discussed by many authors in the literature. Various methods have been described in the literatures which are both subjective as well as objective. The subjective methods include evaluation of aesthetic, phonetics, swallowing and patient comfort. The objective methods comprise of electro myographic records, biting power, utilization of facial measurements ${ }^{2}$.

Different radiographic methods have also been advocated in determining the VDO. Nevertheless, for the object and the subject, more practical method to measure occlusal vertical dimension is the use of facial dimensions Studies were directed to determine the relationship of vertical dimension of rest and occlusion with other facial measurements. These included the distance between the center of pupil to stomion, Chin-Nose distance, glabella subnasion distance, the distance between two angles of the mouth, the distance between two pupils. McGee and Pound in their study considered vertical dimension to be the distance between subnasion and gnathion. However, in the present study, the vertical dimension was measured as the distance between the base of nasal septum and lower border of chin taking into account that the growth of body parts takes place in proportion to each other. The results supported the research hypothesis that there would be a significant relationship between the VDO and the length of fingers. 
The study revealed a sexual dimorphism with higher values for VDO as well as length of fingers in males compared to females. Sexual dimorphism in finger length is related to post-puberty levels of androgen exposure. ${ }^{7}$ Also in this study measurements of only right hand fingers were recorded. This will not create any bias because it is a known fact that physiologically human body maintains physical symmetry. Also, many investigators like Danborno ${ }^{8}$ found no differences in the length of fingers of both hands.

Length of index finger of right hand measured in the present study showed a mean of $70.20 \mathrm{~mm}$ in males and 66.99 $\mathrm{mm}$ in females. This is in accordance with the findings of Danborno ${ }^{8}$ who showed a mean value of $73.54 \mathrm{~mm}$ in males and $69.95 \mathrm{~mm}$ in females. Kanchan et al. ${ }^{9}$ showed a mean value of $64.9 \mathrm{~mm}$ in males and $65.2 \mathrm{~mm}$ in females. Peters ${ }^{10}$ showed a mean value of $72.9 \mathrm{~mm}$ in males and $66.9 \mathrm{~mm}$ in females. We found that length of index finger was a reliable parameter in determination of VDO in females as standard error is +3.67 but standard error in males are higher so it is less reliable in males.In this study, the length of little finger of right hand showed a mean of $59.99 \mathrm{~mm}$ in males and $56.90 \mathrm{~mm}$ in females. This is in accordance with the findings of $\mathrm{Nag}^{11}$ who showed a mean value of $56.3 \mathrm{~mm}$ in females. The study revealed that little finger can also be used for determination of VDO with a standard error of \pm 7.28 in males and \pm 3.67 in females but standard error in males are higher so less reliable in males. Distance from hairline to nasion had standard error of +7.70 in males and +4.20 , so hair line to nasion distance is also partially reliable parameter in case of females to predict VDO.

As these are objective measurements rather than subjective criteria such as resting jaw position ${ }^{12}$ or swallowing ${ }^{13}$ so the guesswork in VDO is eliminated. This method is attractive and practical because it is simple, economic, noninvasive, reliable, requires no radiographs or sophisticated measuring devices and provides reproducible values for future reference. Additionally, it is not time consuming but easy to master unlike earlier methods.

The drawback or limitation of study is that it did not include the subjects with class II, class III and other skeletal or dental malocclusions. Moreover, the subjects were not categorized based on facial forms. Also, the measurement was difficult to record when a patient had a round facial profile with excessive soft tissue bulk under the chin.To authenticate these findings further studies should be carried out comprising of a broad clinical research program that would include the similar analysis for dentulous population in other ethnic groups and then appropriate regression equations may be constructed which can be accepted universally.

\section{Conclusion}

The best parameter to predict the VDO in case of females was length of the little finger. Even distance from hair line to nasion and length of index finger can also predict VDO in females. Because of greater standard error in males, these parameters are less reliable in case of males. Even with the help of regression equation we can make a software which can predict VDO in this digitalized impression Era. As this method is simple, economic, non-invasive, reliable and easily duplicable, it could be recommended for everyday practice.

\section{References}

[1]. Glossary of Prosthodontics Terms $8^{\text {th }}$ edition. J Prosthet Dent 2005;94:10-85.

[2]. Turrell A. Clinical assessment of vertical dimension. J Prosthet Dent 2006;96:79-83

[3]. Orthlieb J, Laurent M, Laplanche O. Cephalometric estimation of vertical dimension of occlusion. J Oral Rehabil 2000;27:802-807.

[4]. Feldman S, Leupold RJ, Staling LM. Rest vertical dimension determined by electromyography with biofeedback as compared to conventional methods. J Prosthet Dent 1978; 40:216-9.

[5]. McGee GF. Use of facial measurements in determining vertical dimension. J Am Dent Assoc 1947;35:342-50.

[6]. Misch CE. Objective Vs. subjective methods for determining vertical dimension of occlusion. Quintessence Int 2000;31:280-2.

[7]. Jackson C. Prediction of hemispheric asymmetry as measured byhandedness from digit length and 2D:4D digit ratio. Laterality 2008;13:34-50

[8]. Danborno B, Adebisi S, Adelaiye A, Ojo S. Estimation of height andweight from the lengths of second and fourth digits in Nigerians.Internet J Forensic Sci 2009;3:2.

[9]. Kanchan T, Kumar GP, Menezes RG, Rastogi P, Rao PP, Menon A, et al.Sexual dimorphism of the index to ring finger ratio in South Indianadolescents. J Forensic Leg Med 2010;17:243-6.

[10]. Peters M, Mackenzie K, Bryden P. Finger length and distal finger extentpatterns in humans. Am J Phys Anthropol 2002;117:209-17.

[11]. Nag A, Nag P, Desai H. Hand anthropometry of Indian women. IndianJ Med Res 2003;117:260-9.

[12]. Atwood DA. A critique of research of the rest position of the mandible.J Prosthet Dent 1966;16:848-54

[13]. Ismail YH, George WA. The consistency of the swallowing technique indetermining occlusal vertical relation in edentulous patients. J Prosthet Dent 1968;19:230-6.

[14]. Silverman MM. Accurate measurement of vertical dimensionby phonetics and the speaking centric space, Part I. Dent Dig1951;57:261-5.

[15]. Benediktsson E. Variation in tongue and jaw position in "s" soundproduction in relation to front teeth occlusion. ActaOdontolScand1958;15:275-303.

[16]. Boyan. Determining vertical dimension of occlusion and centric CR. J Prosthet Dent 1970;24:18-24.

[17]. RuchiLadda, Aruna J Bhandari, Vikrant O Kasat1, Gangadhar S Angadi. A new technique to determine vertical dimension of occlusion from anthropometric measurements of fingers. IJDR 2013;24: 316-320.

[18]. Esan TA, Oziegbe OE, Onapokya HO. Facial approximation: evolution of dental and facial proportions with height. African health science 2012;12: 63-68.

[19]. Nitai Debnath. Relationship of intercondylar distance with inter dental distance of maxillary arch and occlusal vertical dimension: a clinical anthropometric study. Journal of Clinical and Diagnostic Research 2014;8: 39-43.

Tables

Table 1 - Mean of vertical dimension of occlusion, length of index finger, length of little finger and distance from hairline to nasion.

\begin{tabular}{|l|l|l|l|l|}
\hline \multicolumn{3}{|l|}{ nasion. } & MALE & FEMALE \\
\hline & Mean & N & Mean & N \\
\hline measured dimension from hairline to nasion in mm & 61.80 & 200 & 60.36 & 200 \\
\hline $\begin{array}{l}\text { VDO from base of nose to lower border of mandible } \\
\text { in mm }\end{array}$ & 62.20 & 200 & 57.71 & 200 \\
\hline $\begin{array}{l}\text { measured dimension from tip of index finger to the } \\
\text { 3rd crease in mm }\end{array}$ & 70.20 & 200 & 66.99 & 200 \\
\hline measured length of the little finger in mm & 59.99 & 200 & 56.90 & 200 \\
\hline
\end{tabular}


An Alternative Technique To Determine Vertical Dimension Of Occlusion From.....

Table 2 - Sex specific correlations between vertical dimension of occlusion and length of index finger, length of little finger, distance from hairline to nasion.

\begin{tabular}{|c|c|c|c|c|c|c|c|}
\hline & & \multicolumn{3}{|l|}{ Male } & \multicolumn{3}{|l|}{ Female } \\
\hline & & $\begin{array}{l}\text { Measured } \\
\text { Dimension From } \\
\text { Hairline To Nasion } \\
\text { In Mm }\end{array}$ & $\begin{array}{l}\text { Measured } \\
\text { Dimension } \\
\text { From Tip Of } \\
\text { Index Finger } \\
\text { To The 3rd } \\
\text { Crease In Mm }\end{array}$ & $\begin{array}{l}\text { Measured } \\
\text { Length Of } \\
\text { The Little } \\
\text { Finger In } \\
\text { Mm }\end{array}$ & $\begin{array}{l}\text { Measured } \\
\text { Dimension } \\
\text { From Hairline } \\
\text { To Nasion In } \\
\text { Mm }\end{array}$ & $\begin{array}{l}\text { Measured } \\
\text { Dimension From } \\
\text { Tip Of Index } \\
\text { Finger To The 3rd } \\
\text { Crease In Mm }\end{array}$ & $\begin{array}{l}\text { Measured } \\
\text { Length Of } \\
\text { The Little } \\
\text { Finger In } \\
\text { Mm }\end{array}$ \\
\hline $\begin{array}{l}\text { VDO From } \\
\text { Base Of Nose }\end{array}$ & $\begin{array}{l}\text { Pearson } \\
\text { Correlation }\end{array}$ & 0.200 & 0.115 & 0.375 & 0.294 & 0.413 & 0.550 \\
\hline To Lower & P Value & 0.004 & 0.105 & 0.000 & 0.000 & 0.000 & 0.000 \\
\hline $\begin{array}{ll}\text { Border } & \text { Of } \\
\text { Mandible } & \text { In } \\
\text { Mm } & \end{array}$ & $\mathrm{N}$ & 200 & 200 & 200 & 200 & 200 & 200 \\
\hline
\end{tabular}

Table 3 - sex specific regression analyșis

\begin{tabular}{|c|c|c|c|c|c|}
\hline & Dependent Variable & Independent Variable & $\begin{array}{l}\text { Regression } \\
\text { equation }\end{array}$ & $\mathrm{R} 2(\%)$ & SE \\
\hline \multirow{3}{*}{ MALE } & \multirow{3}{*}{$\begin{array}{l}\text { VDO FROM BASE } \\
\text { OF NOSE TO } \\
\text { LOWER BORDER } \\
\text { OF MANDIBLE in } \\
\text { mm (Y) }\end{array}$} & $\begin{array}{l}\text { measured dimension } \\
\text { from HAIRLINE TO } \\
\text { nasion in mm (A) }\end{array}$ & $\begin{array}{l}\mathrm{Y}= \\
45.47+0.271 * \mathrm{~A}\end{array}$ & 4.02 & 7.70 \\
\hline & & $\begin{array}{l}\text { measured dimension } \\
\text { from tip of index } \\
\text { finger to the } 3 \text { rd crease } \\
\text { in mm (B) }\end{array}$ & $\begin{array}{l}Y= \\
55.93+0.089 * B\end{array}$ & 1.32 & 7.80 \\
\hline & & $\begin{array}{l}\text { Measured length of the } \\
\text { little finger in } \mathrm{mm}(\mathrm{C})\end{array}$ & $\begin{array}{l}\mathrm{Y}= \\
22.59+0.660 * \mathrm{C}\end{array}$ & 14.05 & 7.28 \\
\hline \multirow{3}{*}{ FEMALE } & \multirow{3}{*}{$\begin{array}{l}\text { VDO FROM BASE } \\
\text { OF NOSE TO } \\
\text { LOWER BORDER } \\
\text { OF MANDIBLE in } \\
\text { mm (Y) }\end{array}$} & $\begin{array}{l}\text { measured dimension } \\
\text { from HAIRLINE TO } \\
\text { nasion in mm (A) }\end{array}$ & $\begin{array}{l}\mathrm{Y}= \\
44.96+0.211 * \mathrm{~A}\end{array}$ & 8.27 & 4.20 \\
\hline & & $\begin{array}{l}\text { measured dimension } \\
\text { from tip of index } \\
\text { finger to the } 3 \text { rd crease } \\
\text { in mm (B) }\end{array}$ & $\begin{array}{l}Y= \\
30.61+0.404 * B\end{array}$ & 16.57 & 4.00 \\
\hline & & $\begin{array}{l}\text { Measured length of the } \\
\text { little finger in mm (C) }\end{array}$ & $\begin{array}{l}\mathrm{Y}= \\
20.39+0.656 * \mathrm{C}\end{array}$ & 30.06 & 3.67 \\
\hline
\end{tabular}

$\mathrm{A}=$ distance from hairline to nasion, $\mathrm{B}=$ measured dimension from tip of index finger to $3^{\text {rd }}$ crease,

$\mathrm{C}=$ measured length of little finger

\section{Figures}

Fig. 1. Measuring length of index finger

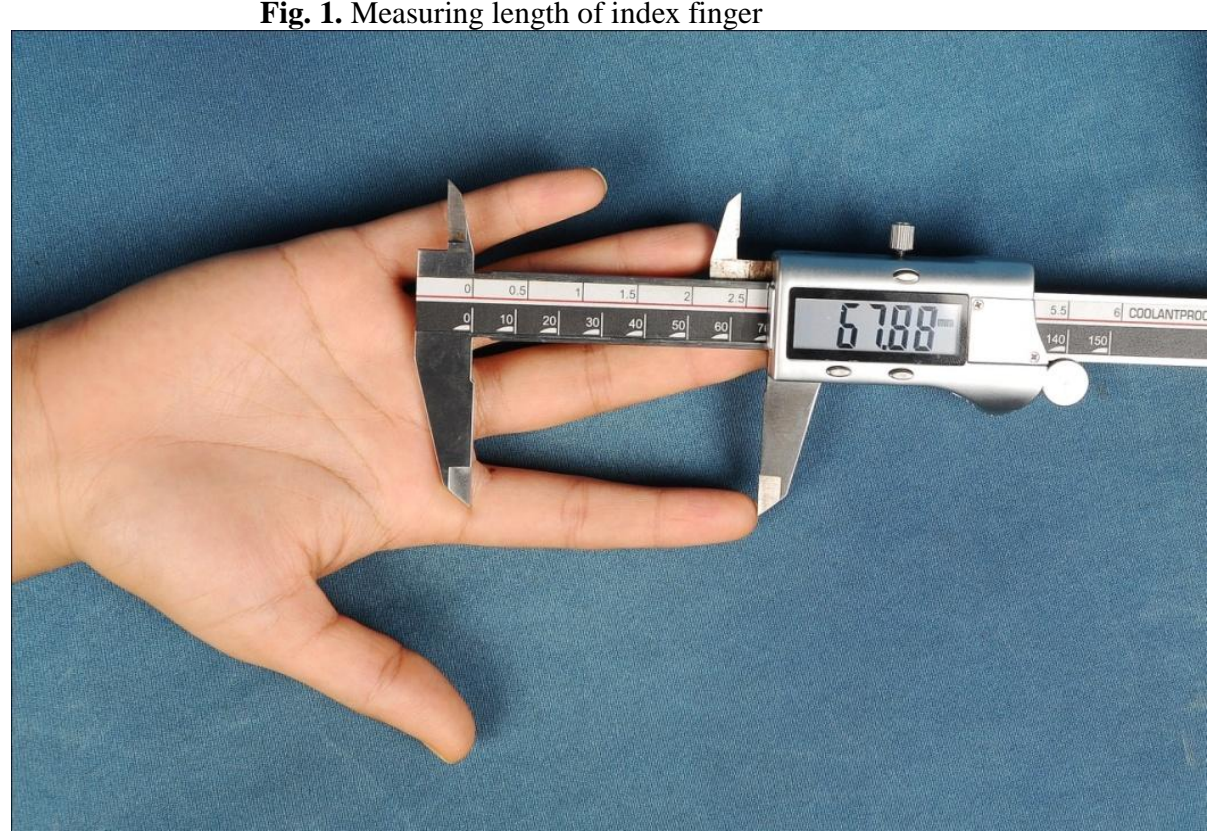


Fig. 2.Measuring length of little finger

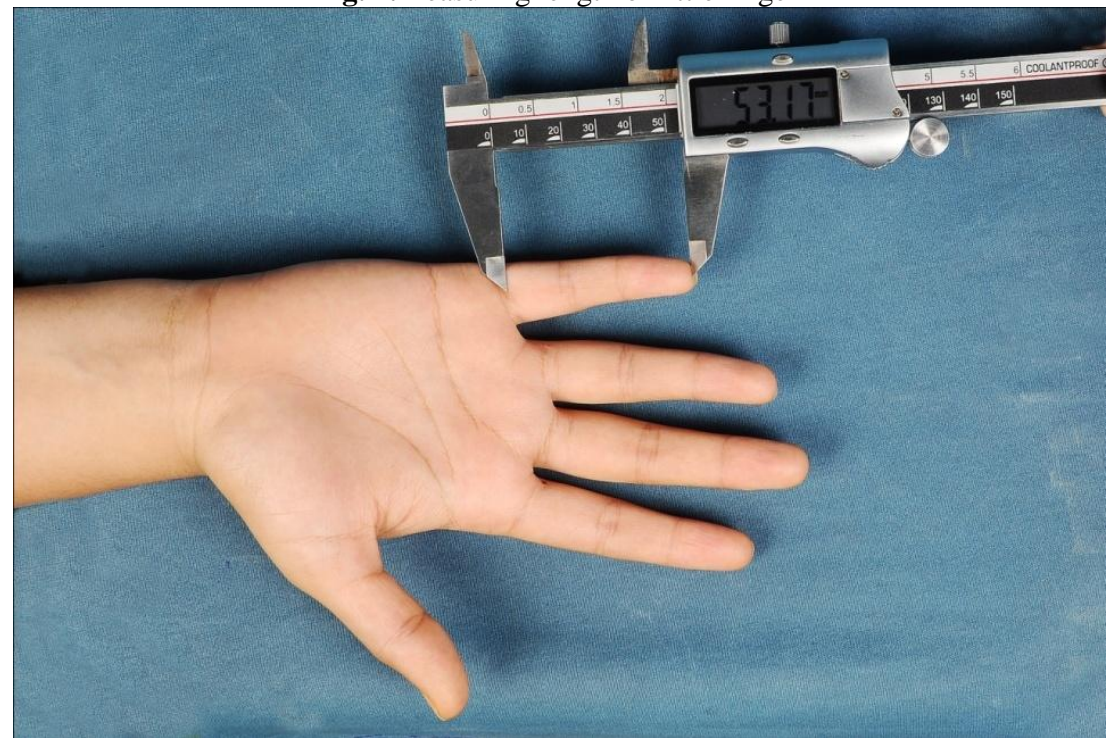

Fig. 3. Measuring the distance from hairline to nasion

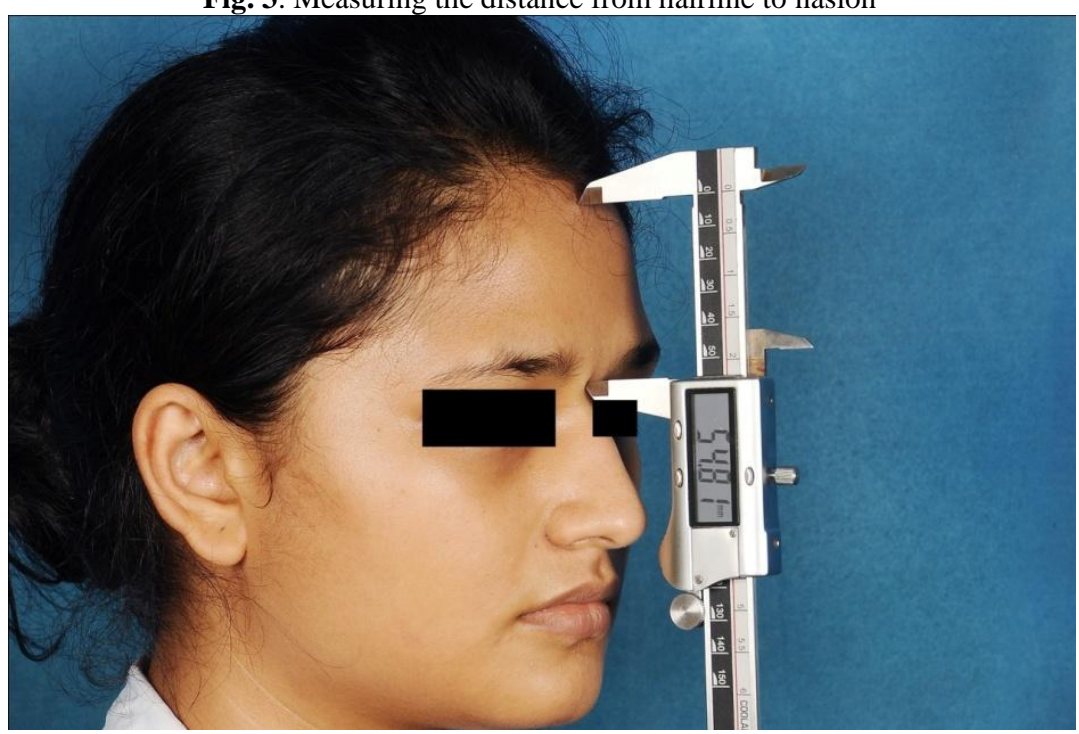

Fig. 4. Measuring vertical dimension at occlusion(VDO)

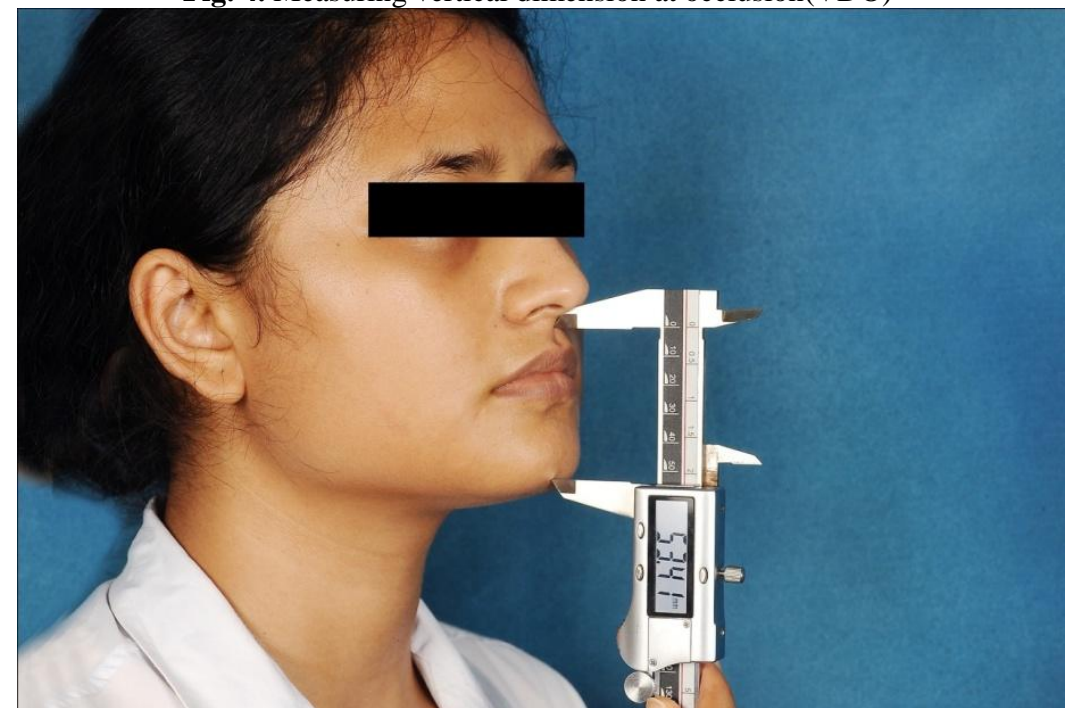

